\title{
Resurgimiento del Sarampión en el siglo 21. El retorno del Rey
}

\section{Resurgence of Measles in the $21^{\text {st }}$ Century. The Return of the King}

\author{
Jaime Rodríguez T. ${ }^{a}$
}

${ }^{a}$ Clínica Alemana de Santiago

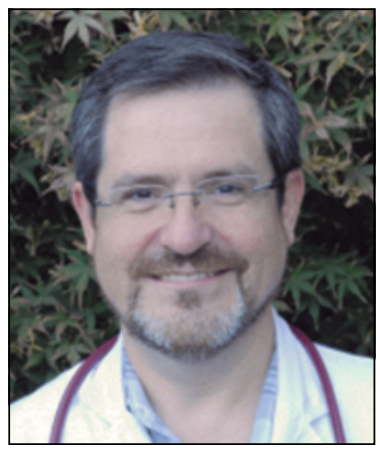

Sarampión es una enfermedad de origen viral (virus RNA género Morbillivirus familia paramyxovirus) altamente contagiosa, aproximadamente el $30 \%$ de los niños desarrolla una o más complicaciones, y estas son más frecuentes en menores de 5 años, desnutridos e inmunosuprimidos ${ }^{1-3}$. A pesar de haber sido controlado gracias a la implementación de eficientes programas de vacunación en la mayoría de países y haber disminuido considerablemente las tasas de morbilidad y mortalidad asociadas, el sarampión aún representa una amenaza para los sistemas de salud pública en diferentes partes del mundo. Con alegría y orgullo tras más de dos décadas de esfuerzo y preparación, la región de las Américas se convirtió en Septiembre de 2016, en la primera en el mundo en ser declarada libre de sarampión. Definida como tal, su eliminación se refiere como "La interrupción de la transmisión endémica del virus del sarampión en todos los países de las Américas por un periodo igual o superior a 12 meses, en presencia de un sistema de vigilancia de alta calidad"4. No obstante, a partir del 2017 la Organización Panamericana de la Salud (OPS) reportó casos confirmados en varios países de la región, muchos fueron importados de otras regiones del mundo, algunos relacionados con importación y otros con fuente desconocida ${ }^{4,5}$. En pleno siglo 21 y a pesar de existir una vacuna segura y eficaz, el sarampión se mantiene como foco de preocupación a nivel mundial, permanece como una de las principales causas de muerte en niños pequeños, se estima que en 2016 murieron 89.780 personas por esta causa, la mayoría de ellas menores de 5 años ${ }^{6}$.

Para entender las razones del despertar de este gigante dormido que pensábamos teníamos controlado y a punto de erradicar, debemos revisar algo de historia $\mathrm{y}$ conceptos generales de inmunidad.

El Sarampión fue una de las enfermedades consideradas obligatorias de la infancia, aparentemente de origen zoonótico (peste bovina) evolucionó de un virus ancestral y nos acompaña hace más de 5000 años, desde que la población agraria del Medio Este fue suficientemente grande para mantener la transmisión del virus y existía un estrecho contacto entre el ganado y los hombres ${ }^{7}$. No fue inicialmente de distribución universal, su llegada al continente americano en el siglo XVII por los colonizadores europeos causó cientos de muertes entre los nativos, lo que facilitó la conquista $^{8}$. Antes de que la vacuna se introdujera en 1963 y se generalizara su uso, cada 2-3 años se registraban importantes epidemias que llegaban a causar cerca de 30 millones de casos y dos millones de muertes al año en el mundo.

La infección natural confiere inmunidad perenne. En 1846 un médico Danés Peter Panum en un brote en Islas Faroe observó que la población adulta que 
tuvo sarampión en 1781 no presentó un nuevo contagio. Aunque las bases inmunológicas de la protección a largo pazo de la infección natural no están bien establecidas, los trabajos de Panum mostraron las bases y la importancia epidemiológica de la inmunidad de rebaño y el tamaño crítico de la población para generar protección?.

La eficacia protectora dada por la vacuna (virus vivo atenuado) es excelente, sin embargo no es absoluta. Debido a que la mayoría de lactantes pierde los anticuerpos maternos protectores entre los 9 y 12 meses, se recomienda aplicar la primera dosis de vacuna SRP (sarampión, rubéola y parotiditis) entre los 12 y 15 meses $^{10}$. La falla primaria de la vacuna (el receptor no desarrolla protección con la vacunación) depende de factores del huésped como el estado nutricional, la inmunidad y la edad de administración de la vacuna (92,5\% producen Anticuerpos IgG cuando se administra al año de vida, $84 \%$ entre los 9-11 meses), esto dado por interferencia con anticuerpos maternos IgG y la inmadurez inmunológica del huésped los primeros meses de vida. De aquellos que no responden a la primera dosis el 95\% responde a una segunda dosis generando buenos niveles de IgG. Por esta razón la OMS recomienda que todas la persona reciban 2 dosis de vacuna que contenga sarampión (ej. SRP). A diferencia de la infección natural la inmunidad dada por vacuna no es permanente. La falla secundaria se refiere a individuos que tienen buena respesta a la inmunidad primaria y pierden protección a lo largo del tiempo, en sarampión la falla secundaria parece tener menor importancia, los casos de sarampión descritos con 1 o 2 dosis de vacunas son menos que en población no vacunada y menos severos, sin embargo genera un desafío a largo plazo dado la falta de exposición natural al virus en la población ${ }^{11}$.

Dado que la vacuna genera protección adecuada, es de vital importancia entender las razones de este aumento progresivo del sarampión a nivel mundial.

El sarampión es contagioso desde los 4 días antes hasta los 4 días después de la aparición del exantema, lo cual facilita la transmisión del virus previo al diagnóstico, además muchos médicos y trabajadores de la salud nunca han visto casos, lo cual contribuye a su reconocimiento tardío y a atrasos en su reporte epidemiológico consecuentemente no se logran tomar las medidas de contención en forma oportuna.

Como vimos la falla inmunidad primaria y en algunos casos una falla secundaria pueden explicar la aparición de algunos casos de la enfermedad, sin embargo estos mecanismos no explican la aparición de brotes epidémicos en algunas regiones del mundo. La falta de cobertura adecuada en vacunas ( $1^{\mathrm{a}} \mathrm{o} 2^{\mathrm{a}}$ dosis) es en la actualidad el principal problema. Para lograr mantener el efecto rebaño y prevenir la aparición y propagación de brotes, se requieren tasas de coberturas contra el sarampión, de entre el 96 y el 99\%. Es así como los brotes pueden ocurrir en comunidades y regiones aún con coberturas de vacunación entre el 90 y el 95\%. Los factores que afectan las coberturas a vacunas son diversos desde la falta de acceso, factores sociopolíticos y económicos favorecidos por guerras, migraciones masivas, crisis políticas, etc. No obstante en países desarrollados el problema es diferente. La falta de confianza en las vacunas (calificado por la OMS como uno de los principales 10 problemas graves de salud) promovido por los grupos antivacunas y las falsas percepciones de la relación de la vacuna SRP con autismo han sido uno de los principales problemas en países desarrolla$\operatorname{dos}^{11,12}$. La propagación de esta falsa percepción a través de redes sociales tiene cada vez más relevancia y el daño producido ha tenido consecuencias nefastas en la salud de la población.

Desde que se introdujo la vacuna contra el sarampión en Chile en 1964, se ha logrado una reducción significativa de las tasas de morbilidad y mortalidad por esta enfermedad, en la actualidad nuestros casos corresponden a casos importados o relacionados con importación. En este contexto, la sospecha y confirmación diagnóstica son claves; el diagnóstico de sarampión debe basarse en tres elementos: cuadro clínico, epidemiología y laboratorio. Para su confirmación diagnóstica se dispone de pruebas serológicas con mediciones de IgG e IgM específicas, biología molecular con aplicación RPC-TR y aislamiento viral. Resulta relevante recalcar que los títulos de IgM, que son confirmatorios de enfermedad, se detectan desde el $3^{\circ}$ día del exantema y se mantienen positivos por 30 a 60 días en la mayoría de los sujetos enfermos y que en individuos vacunados previamente no se detectan niveles elevados de $\operatorname{IgM}^{13}$.

En este escenario ¿Podremos ganar la batalla contra el sarampión? La vigilancia epidemiológica, diagnóstico oportuno, y en especial las coberturas adecuadas de vacuna han demostrado ser eficientes en el control de la enfermedad. La erradicación del sarampión probablemente tarde más de lo que se teníamos en mente, la falta de buenas coberturas de vacuna especialmente de 2 dosis en diferentes partes del mundo ha demostrado la frágil que somos frente a antiguos enemigos. En poblaciones altamente vacunadas y con buenos sistemas de vigilancia como en Chile, los brotes se presentan en pocos casos y de rápido control, lo que indica inmunidad de protección en la comunidad a pesar su envejecimiento. Ganaremos la batalla, sin duda, probablemente más adelante.

\section{Conflicto de intereses}

El autor declara no tener conflicto de intereses. 


\section{Referencias}

1. Duke T, Mgone C S. Measles: not just another viral exanthem Lancet. 2003;361:763-73.

2. Moss W, Griffin D. Measles. Lancet. 2012;379:153-64.

3. Robbins FC. Measles: clinical features. Pathogenesis, pathology and complications. Am J Dis Child. 1962;103:266-73.

4. OPS-OMS, oficina regional de las Américas. La región de las Américas es declarada libre de Sarampión. (Comunicado de prensa) 27 septiembre 2016. [Accedido 14-04-19] Disponible en: http://www.paho.org/hq/index. php?option=com_content\&view=article\& $\mathrm{id}=12528 \% 3$ Aregion-americas-declaredfree-measles\&lang=es.
5. World Health Organization. Measles vaccines: WHO position paper, April 2017 - Recommendations. Vaccine. 2019 7;37(2):219-22.

6. World Health Organization. Measles. [Accedido 15-04-19] Disponible en https://www.who.int/immunization/ diseases/measles/en/

7. Rota PA, Moss WJ, Takeda M, De Swart RL, Thompson KM, Goodson JL. Measles. Nat Rev Dis Primers 2016;2:16049.

8. Delpiano L, Astroza L, Toro J. Sarampión, la enfermedad, epidemiología, historia y los programas de vacunación en Chile. Rev Chil Infectol 2015;32(4):417-29.

9. Moss W. Measles in vaccinated individuals and the future of measles vaccination. Clin Infect Dis. 2018;67(9):1320-1.
10. Ulloa-Gutiérrez R, Morice-Trejos A, Ávila-Agüero ML. El regreso del sarampión. Acta Méd Costarric. 2017;59(4):128-9.

11. McHale P, Keenan A, Ghebrehewet S. Reasons for measles cases not being vaccinated with MMR: investigation into parents and carers views following a large measles outbreak. Epidemiol Infect 2016;144:870-5.

12. Siani. Measles outbreak in Italy: A paradigm of the re-emergence of vaccine-preventable diseases in developed countries. Preventive medicine. 2019;121: 99-104.

13. Strebel PM, Papania M, Gastañaduy P, Goodson J. Chapter 35 -579-618. Measles vaccine. In: Offit SA, Plotkin WA, Orenstein PA (eds.). Vaccines (7th Edition). Philadelphia, Elsevier. 